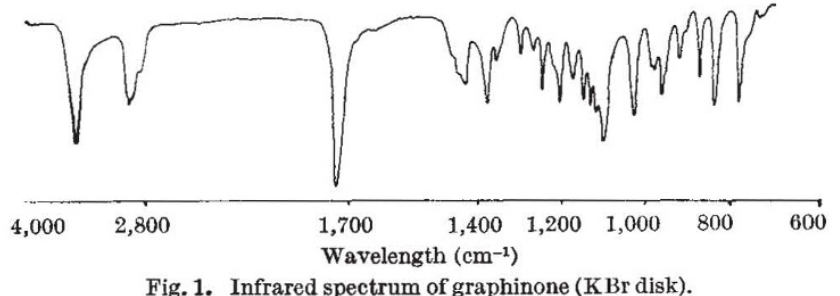

Bioassay $^{1}$ revealed that the weakly acidic-neutral fraction was biologically active. The extract was analysed by thin-layer chromatography (silicic acid developed in ethyl acetate/hexane, $1: 1$ ) and the active component was located at $R_{F}$ value $0 \cdot 6-0 \cdot 7$. The weakly acidic-neutral fraction was chromatographed on a silicic acid column developed with ethyl acetate/benzene, 1:9, and the active fractions were combined and reduced under vacuum. The residue was recrystallized from benzene-hexane to yield colourless needles. We propose to call this substance "graphinone".

Graphinone has a melting point of $93^{\circ}-94^{\circ} \mathrm{C}$ and $[\alpha]_{y}^{22}-75^{\circ}$, where $c=1$, methanol, and gave a positive reaction with ketone and epoxide reagents. The ultraviolet spectrum had an absorption maximum at $275 \mathrm{~nm}$ $(\varepsilon 78)$ and the infrared spectrum, illustrated in Fig. I, had bands at $3,480,1,739,1,382,1,252,1,106$ and 835 $\mathrm{cm}^{-1}$. The molecular formula, $\mathrm{C}_{16} \mathrm{H}_{24} \mathrm{O}_{5}$, was determined by high resolution mass spectroscopy: m/e observed $=296 \cdot 1631$; calculated mass for $\mathrm{C}_{16} \mathrm{H}_{24} \mathrm{O}_{5}=296 \cdot 1624$.

Graphinone stimulated lettuce seed germination at a concentration of less than 1 p.p.m., and maximum stimulation was obtained between 10 and 50 p.p.m. (Table 1). Higher concentrations resulted in a decrease in the stimulatory effect. The growth of lettuce seedlings was inhibited by concentrations greater than 25 p.p.m.

Table 1. EFFECT OF GRAPHINONE ON THE GERMINATION OF LETTUCCE SEEDS

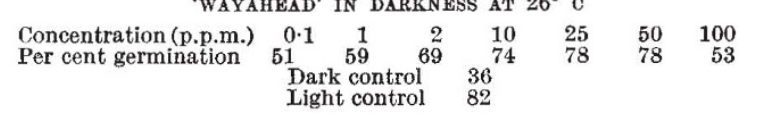

Table 2. EFFECT OF GRAPHINONE ON THE GROWTH OF RADISH LEAF DISKS IN IIGHT AT $30^{\circ} \mathrm{C}$ FOR 20 HOURS

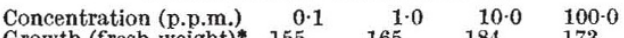

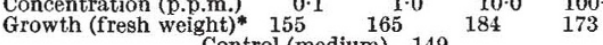

Control (medium) 149

* Growth is shown relative to fresh weights of radish leaf disks before incubation.

Graphinone will promote the growth of radish leaf disks ${ }^{2}$, and Table 2 shows that maximum promotion was given by 10 p.p.m. These effects of graphinone resemble those of gibberellin and kinetin, but graphinone showed no activity in the rice seedling or oat senescence tests at concentrations of up to 100 p.p.m. Gibberellin, kinetin, thiourea and nitrate ions are known to promote germination of seeds requiring light such as lettuce or tobacco ${ }^{3}$. A naturally occurring germination stimulant has recently been isolated from cotton root exudates ${ }^{4}$. This substance, strigol, is effective in witchweed (Striga lutea Lour.). Graphinone is a new, biologically active substance, quite distinct in its physicochemical and biological properties.

We thank Dr H. Sakai for identification of the fungus.

$$
\begin{aligned}
& \text { T. Sassa } \\
& \text { H. Kaise } \\
& \text { Y. Ogawa } \\
& \text { K. MUnakata }
\end{aligned}
$$

Laboratory of Pesticides Chemistry,

Department of Agricultural Chemistry,

Nagoya University,

Nagoya, Japan.

Received March 7, 1969.

${ }^{1}$ Ikuma, H., and Thimann, K. V., Plant and Cell Physiol., 4, 169 (1963).

${ }^{2}$ Kuraishi, S., and Okumura, F. S., Bot. Mag. Tokyo, 68, 301 (1956)

${ }^{3}$ Amen, R. D., The Botanical Review, 34, 1 (1968).

${ }^{4}$ Cook, C. E., Whichard, L. P., Turner, B., Wall, M. E., and Egley, G. H., Science, 154, 1189 (1966).

\section{ATP in Sieve Tube Sap from Willow}

Hypotheses explaining the mechanism of longitudinal sieve tube transport in higher plants can be divided into two groups. First there are the hypotheses, typified by the pressure flow hypothesis of Münch ${ }^{1}$, in which energy for the transport process need only be applied at either end of the transport system, the sieve tubes themselves being metabolically inert. On the other hand, hypotheses such as the electro-osmotic mechanism proposed by. Spanner ${ }^{2}$, or the transcellular streaming hypothesis of Thaine ${ }^{3}$, would require a continuous expenditure of energy. throughout the whole length of the sieve tubes. Ultristructural studies on phloem have as yet failed to produce any unanimity as to the metabolic capabilities of sieve elements $s^{4,5}$.

An obvious method of determining whether energy is readily available for transport in sieve tubes is by measuring ATP concentrations in sieve tube exudates Kluge and Ziegler ${ }^{6}$ have already analysed exudates from a variety of species, and have found concentrations of ATP within the range $0 \cdot 03-0.30 \mu \mathrm{g} / \mu \mathrm{l}$. Kluge's data, however, may be subject to error, because the exudates were obtained from gross incisions into the phloem, and the ATP concentrations measured may not have been a true reflexion of the concentrations within the sieve tubes. We therefore decided to measure ATP concentrations in sieve tube sap obtained from willow through the severed stylets of the aphid T'uberolachnus salignus (Gmelin), because we believed that this method would yield unadulterated samples of sieve tube sap. The samples of sap were obtained from stylets situated on segments of 2-3 year old willow stem, and the ATP concentrations were determined using Firefly Lantern Extract (Sigma Biochemical Co.). Light output from the reaction mixture was measured by a pulse counting technique using a single photomultiplier system connected to a scaler?

Table 1. ATP CONCENTRATIONS IN SIEVE TUBE SAP

$\begin{array}{ccc}\text { Date of experiment } & \begin{array}{c}\text { Rate of exudation } \\ (\mu \mathrm{l} . / \mathrm{h})\end{array} & \begin{array}{c}\text { ATP concentration } \\ (\mu \mathrm{g} / \mu \mathrm{l} .)\end{array} \\ 3.3 .69 & 1.231 & 1.335 \\ 6.3 .69 & 1.482 & 0 \cdot 584 \\ 10.3 .69 & 1 \cdot 900 & 0.603 \\ 11.3 .69 & 2 \cdot 676 & 0.892 \\ 13.3 .69 & 1.683 & 0.837\end{array}$

Table 2. ATP CONCENTRATIONS OVER $\triangle$ PERIOD OF HOURS

$\begin{array}{lcccccc}\text { Time (h) } & 1 & 2 & 3 & 4 & 5 & 6 \\ \text { of exudation } & 1.808 & 1.469 & 1.416 & 1.765 & 1.788 & 1.415 \\ \text {. } / \mathrm{h} \text { ) } & & & & & & \end{array}$

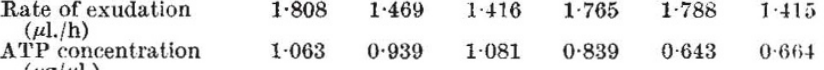
$(\mu \mathrm{g} / \mu \mathrm{l}$.)

Table 1 presents the concentrations of ATP found in sieve tube sap from a number of experiments. These data show that the ATP concentrations are higher than those found by Kluge and Ziegler. Moreover, the data in Table 2 show that the high concentrations of ATP are not merely transient phenomena produced by severance of the aphid stylets, but can be maintained over a period of hours.

High concentrations of ATP are present in sieve tube sap; how the energy from this substance is applied to the translocation mechanism remains to be discovered. Clearly, however, energy supplies are available within tho sieve tubes to drive a cytoplasmic streaming system.

D. C. J. GARDNER

Department of Botany,

A. J. PEEL

University of Hull.

Received April 1, 1969.

1 Münch, E., Die Stoffbewegung in der Pflanze (Fischer, Jena, 1930).

${ }^{2}$ Spanner, D. C., J. Exp. Bot., 9, 332 (1958).

3 Thaine, R., J. Exp. Bot., 13, 152 (1962).

${ }^{4}$ Esau, K., and Cheadle, V. I., Bot. Gaz., 124, 79 (1962).

${ }^{5}$ Kollman, R., Phytomorphology, 14, 247 (1964).

' Kluge, K., and Ziegler, H., Planta, 61, 167 (1964).

${ }^{7}$ Lyman, G. E., and De Vincenzo, J. P., Anal. Biochem., 21, 435 (1967). 